\title{
1 Energy-Water Nexus Design and Operation towards the 2 Sustainable Development Goals
}

3 Xiaonan Wang ${ }^{\mathrm{a}, *}$, Koen H. van Dam ${ }^{\mathrm{b}}$, Charalampos Triantafyllidis ${ }^{\mathrm{c}}$, Rembrandt H.E.M.

$4 \quad$ Koppelaar $^{\mathrm{b}, \mathrm{d}}$, and Nilay $\mathrm{Shah}^{\mathrm{b}}$

$5 \quad{ }^{a}$ Department of Chemical and Biomolecular Engineering, National University of Singapore, Singapore

$6 \quad 117585$

$7 \quad{ }^{b}$ Centre for Process Systems Engineering, Dept. of Chemical Engineering, Imperial College London,

8 South Kensington, London, SW7 2AZ, UK.

$9{ }^{c}$ Smith School of Enterprise and the Environment, University of Oxford, South Parks Road, Oxford, $10 O X 13 Q Y, U K$

${ }^{d}$ Centre for Environmental Policy, Imperial College London, South Kensington, London SW7 2AZ, UK

*Email: chewxia@nus.edu.sg

Tel: +65 66016221

14

\section{Abstract}

Urbanization is taking place rapidly, while the planning of energy, water and resource capacities in many cities especially in developing countries is lagging behind. Motivated by the lack of transparent data-driven decision-making support, a systematic methodology to support sustainable development emphasizing the energy-water nexus and multiple resource systems is developed. It serves as an opensource integrated tool to advice the planning and operation considering social, environmental and economic sustainability globally. Several applications of the platform are demonstrated based on a subSaharan African metropolitan area. The outputs depict energy, water, and other resource demand, supply and transport on multiple spatiotemporal scales, which are used to indicate cost effective and environmentally friendly development strategies. The total Greenhouse Gas emissions associated with the nexus are minimized to 0.56 tonnes $\mathrm{CO}_{2}$ equivalent per capita in 2030, resulting to a $51.4 \%$ reduction compared with the business-as-usual scenario, while providing sufficient resources to address sustainable development goals.

Key words: Energy-Water nexus; decision making; supply and demand; environment; design and operation 
The sustainable provisioning of water, energy, and other resources for growing populations and the subsequent processing and management of waste and pollution are recognized as fundamental issues for human society (Menger-Krug et al., 2013; Ramaswami et al., 2016). It is predicted that more than $70 \%$ of the population in the whole world will live in cities by 2050 , making urbanization essential to be considered in governmental decisions (Clark, 2003). The associated resource demand and supply become a major challenge in designing and operating city infrastructures such as electricity, water, gas, and transport networks, as well as wastewater and municipal solid waste handling (Bai et al., 2011; Lorek and Spangenberg, 2014). Many global and regional initiatives have been formed to provide feasible solutions to facing urban water and energy systems and therefore guide sustainable development (Lu et al., 2015; Urbaniec et al., 2016; Weitz et al., 2015). The United Nations Rio+ 20 summit committed member states to launch a set of Sustainable Development Goals (SDGs) (Griggs et al., 2013; United Nations General Assembly, 2015), for which both water and energy are vital to the delivery of city services and interlinked as a nexus in urban design and operation. Urban water and wastewater utilities consume a considerable amount of energy to provide water supply and sanitation services. At the same time, the generation of electricity and heat requires reliable water sources. These are addressed in SDG 6 to ensure availability and sustainable management of water and sanitation for all, and SDG 7 to guarantee universal access to modern energy services with improved efficiency and increased renewable sources (Chen and Chen, 2016; Hussey and Pittock, 2012; Zhang and Anadon, 2013).

However, joint achievement of multiple SDG targets was rare and many concerns have been raised about its feasibility (Gao and Bryan, 2017). Existing models for city simulation, planning, and optimization are normally domain based, and there exists a gap for an integrated platform using bottom-up tools to account both human behaviours and technology advances especially in energy, water, and resource sector (Wang et al., 2018). Current widely adopted energy systems analysis tools such as HOMER (Brandoni and Bošnjaković, 2017; Lambert et al., 2006) and TIMES (Daly and Fais, 2014) seldom addresses the interlink with other resource systems, facing both engineering and socio-technical complexities. On the other hand, the macro economy is only simulated at the level of aggregate sectors restricting capability to measure income distributions at the individual level (Kilkiş, 2016). A systematic approach is lacking to assess cross-effects of multiple plans and designs, and thereafter evaluate optimal strategies to inform infrastructure investment and operation decisions to reach development targets, letting alone utilizing limited funds as effectively as possible in real-world policy making (Nilsson et al., 2016; Villarroel Walker et al., 2014). The rapid population growth and large scale pollution of fresh water by industries has 
resulted in an urgent need to roll out affordable water and wastewater treatment technologies (Gleick and Ajami, 2014). Similar problems exist in the energy sector in terms of delivering reliable supply through clean energy technologies with minimal risk of supply disruptions (Kemausuor et al., 2011; Mandelli et al., 2014).

Computer simulation and optimization tools can provide substantial decision support by test the feasibility of emerging technologies ex-ante and investigate whether implementation will be impactful (Hering et al., 2013; Lam et al., 2017). It is thus imperative to fill the gap in sustainability-aware planning by building an integrated decision support system that can convey the present situation with suggested solutions for decision makers aided by intelligent models (Coutinho-Rodrigues et al., 2011; Fiksel, 2003). Moreover, energy equity especially for developing countries cannot be neglected in the rapidly evolving smart city landscape (Anadon et al., 2015). The implementation of programmes to reach SDG targets is to be carried out from international to city scales for worldwide prosperity in the long term. We have therefore developed the resilience.io platform as an open-source test bed to enhance the understanding of urban socio-technical systems by providing insights on both current and future resource demand and supply, especially those implied by affecting the SDGs under various social, economic and environmental scenarios. Its effectiveness has been validated through a series of initial applications in Africa ("Case Studies resilience.io," 2017).

This work has developed an integrated platform to deal with the above-mentioned challenges. Section 2 will first describe the overall framework, data structure, and workflow of the platform, followed by further discussions of the three core components, i.e., socialdemographics, resource demand, and supply technologies respectively. Section 3 illustrates how the whole framework is applied to a city region to achieve the cost effective and resilient development strategies of the energy-water nexus. Conclusions are discussed in Section 4 with future work proposed.

\section{Framework and methodology: Sustainable, Resilient and Smart Cities}

The resilience.io platform can model the spatiotemporal economics of a city and its hinterland, hereby to create visibility on interconnected use of water, energy and material resources, and the impacts of technology, policy, and planning decisions to improve the management of resource flow and utilisation. A series of economic, environmental, and social impact metrics are accounted. Current city demographics, infrastructure and social-economic information published by government are fully taken as the initial state of the studied urban region. Detailed spatial and temporal resource and demand for the present and future situation, obtained by multi-agent 
simulation, are generated to examine existing the capacity utilization and the needs for future expansions. Supply-side matching is carried out on an economic and environmental cost optimal basis. Three different approaches are combined to materialize the platform as illustrated in Fig. 1 for the entire framework with a user interface linked to the studied region.

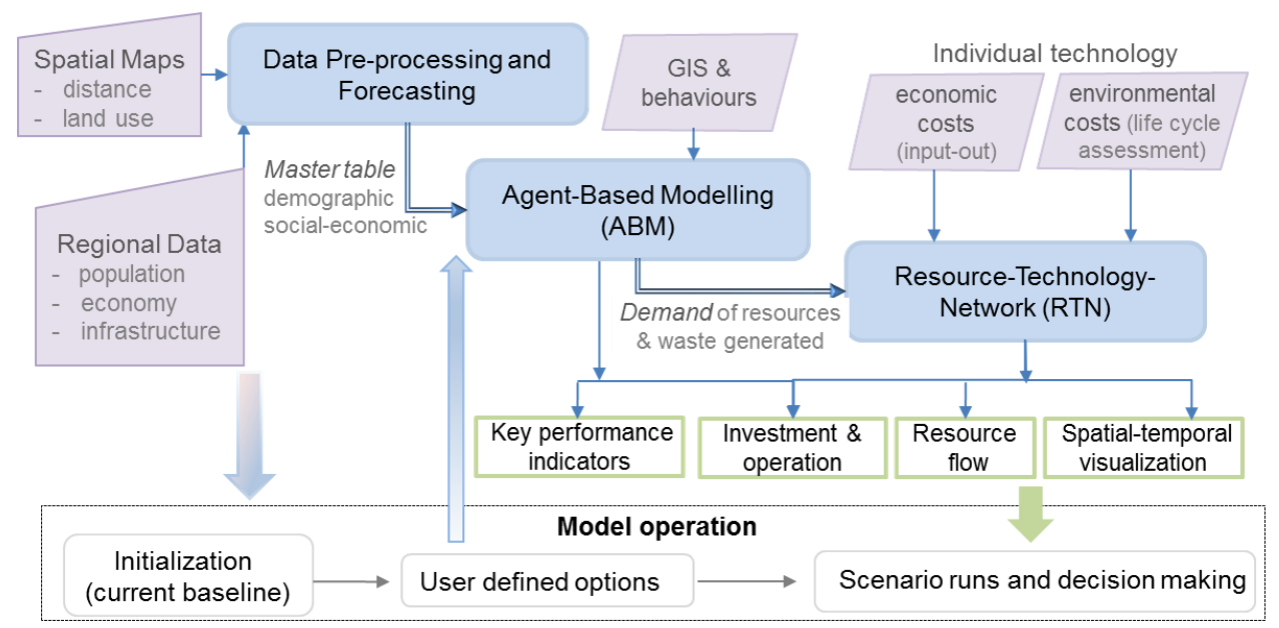

(a)

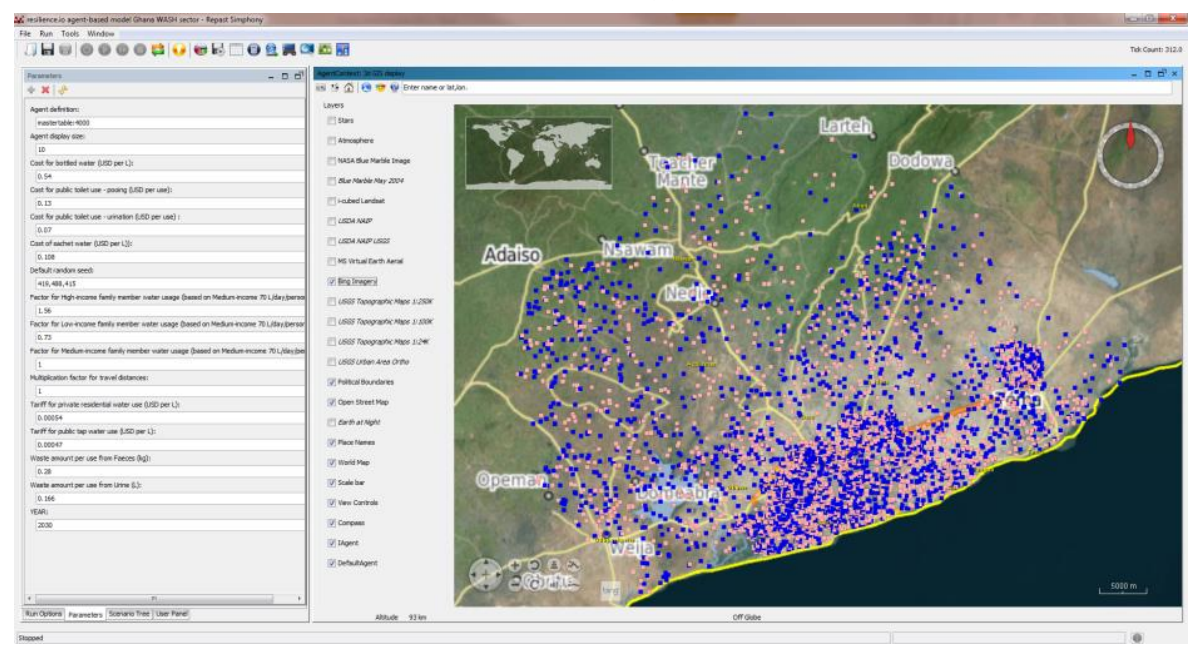

(b)

Fig. 1 Using the resilience.io decision support platform to collaboratively plan urban water, energy and resource systems: (a) Workflow of the platform; (b) GIS-based simulation interface.

The developed platform and results are able to promote a systematic understanding of urban metabolism and resource systems by incorporating three distinct components interconnected with input and output data. The starting point is the regional datasets which describe the population and its characteristics, such as income status and infrastructure access. These parameters are preprocessed into one spreadsheet, namely a population master table, where each row denotes the 
number of population members with a unique set of characteristics. The demographics module as the first component to provide input for further simulation and optimization, updates the number of people in each category based on birth rates, death rates, migration and economic changes. The updated master table for future years forms the basis for the demand simulation. Similarly, a second table for characteristics of commercial, institutional and industrial users is also built based on preprocessing the raw data: registered water users at the Ghana Water Company (GWC) combined with validated localised water use statistics. Second validations were carried out to ensure bottomup estimates were valid with total top-down aggregate water use measured by GWC (Koppelaar et al., 2018). The second table is also updated in the demographics module. These master tables lay the foundation for further analysis of the demand side management for water, energy, and many other resources through a bottom-up approach, realized by the second model component of AgentBased Modelling (ABM). It generates a synthetic population from the master table datasets and simulates their activities correspondingly. The behaviours of agents then lead to the real-time demand of water, energy and waste treatment. The results of demand vectors that need to be met in current and future years from the ABM simulation are further used as input data, along with the spatially outlined existing infrastructure with its technological specification to conduct the supplyside matching. It is implemented through Resource-Technology Network (RTN) optimization accounting economic, environmental, and even social objectives, as the end point module in the platform's articulation (Dimitriadis et al., 1997; Samsatli et al., 2015).

To assure its open-source non-commercial nature to support urban development at any level, the whole platform is built from scratch in Java. Users are allowed to define input parameters, such as the social-demographic parameters, the behavioural rules and the economic metrics through the user interface. Several input and output file formats are adopted for data transferring between modules, including Geographic Information Systems (GIS) with shape files for spatial analysis and visualization, database files for data input, transfer and storage, and mathematical packages to enable faster solutions and accommodate large scale problems. The output values are analysed with a series of post-optimization calculations and adjust the inputs through a feedback loop.

This section elaborates on the model components by first describing demographic and socioeconomic data processing and model construction on multiple spatiotemporal scales. The ABM simulation component follows to show how to establish the methodology to generate useful demand files as results. The last part continues to describe in detail the functional specifications of the RTN optimization model, including the interpretation of input data and output visualization. 
This model component can generate and update the socio-demographic and economic data in any future years selected by users. A population master table is created, in which each row states the number of people with a unique set of characteristics (e.g. city district, gender, age, employment, income and infrastructure access). These values are integrated based on a distribution of the full set of variables from open sources and locally collected data, thereby containing all possible combinations of characteristics with the number of population members and households that have this set of values. The variable distribution in the master table was built using ranking-based sequential association of characteristics informed by the relations of household types with certain socio-economic characteristics and access to facilities.

The calculations are done on a yearly basis, such that a new master table is generated for the simulated forward year based on that of the previous year. All significant factors to demographic changes are considered, including the rate of births, deaths, ageing, immigration and emigration, and employment change. After updating population age, for each spatial area and category, the number of people in that category are updated via:

$$
\begin{aligned}
\text { Population }(t+1) & =\text { Population }(t)+\text { Births }(t)-\text { Deaths }(t) \\
& + \text { Immigrations }(t)-\text { Emigrations }(t)
\end{aligned}
$$

The parameters used in the model are specified according to interrelations, such as death rates per age group and migration based on existing location patterns. The demographic change rates are applied to each category, as a row in the table, proportionally to the number of people so that the distribution between household types is fixed. After an estimation of demographic changes in population, adjustments can be further made to evaluate different socio-economic scenarios (e.g., the ratio of employed people, income level changes etc.). It is assumed that employment will grow from the current situation to a maximum level $\left(E_{\max }\right)$ according to the regional characteristics. The parameter of employment change rate $(E C R)$ can be estimated following a logistics S-curve type function with respect to the variable of employment ratio $\left(r_{e m p}\right)$ (Hastings, 2013), which is implemented as:

$$
\operatorname{ECR}(t)=0.05 \times r_{\text {emp }}(t) \times\left(1-\frac{r_{\text {emp }}(t)}{E_{\text {max }}}\right)
$$

Similarly, the master tables containing non-residential information are also simulated. The numbers of companies and institutes can be forecasted from societal economic information, or updated based on population and economic evolvement if no direct data available. An example is given by equation (3), which suggests that a higher employment change rate $(E C R)$ and more employment in a sector implies more companies and thus more resource requirements. 


$$
N_{\text {company }}(t+1)=N_{\text {company }}(t) \times(1+E C R(t))
$$

171 It is noted that while the population data is cumulative, a limit was implemented on years to be simulated 172 (e.g., 20 years from a base year of 2010 until 2030), as the results would become less and less realistic 173 if extrapolated too far into the future. The strength of the proposed models is relying on the widely 174 available information in terms of key social-demographic and economic indicators from international 175 and regional census and reports for historical records.

Agent-based simulation models make the next key component of the platform. Agent-Based Modelling, as a computational method that builds models composed of autonomous agents to interact within an environment, enables simulating the dynamics of a complex system (Jackson, 2010). The 'ODD' (Overview, Design concepts, and Details) protocol as a standard layout for describing individual- and agent-based simulation models is adopted in this session to explain the modelling structure and simulation techniques (Grimm et al., 2010, 2006).

First of all the purpose of using ABM in this work is to provide solutions for urban resource systems planning through an integrated decision support platform, which is desired for sustainable city development combining bottom-up and top-down approaches. ABM can model resource consumption patterns in a bottom-up approach directly linked to human activities, taking a variety of sectors such as residential, commercial, industrial, and transportation into account. Since this approach simulates individual agent's behaviours over time, it can be regarded as a spatially explicit micro-simulation process that is capable of involving each unique entity's behavioural characteristics and goals.

Next the full set of state variables is described. The low-level variables associated with individuals include age, gender, work force, income rank, home location, and access to infrastructure related to resource use. Therefore agents' behaviours and consumption strategies are distinguished by the combination of characteristics. The higher-level entities are then formed by a population consisting of individuals within each zone or functional region. Finally, the model's spatial and temporal scales can be defined according to different planning purposes. For example, the model loads a map of all districts in the focused region from geographic shape files in the case study, and creates a number of agents with each drawing characteristics from a row in the corresponding year's master table to populate this area through a stochastic process. The simulation is conducted over any long-term period (e.g., a whole day of 24 hours) by tracking the states of all agents every 5 minutes. 
The process overview and scheduling is elaborated below. Agents here represent individual citizens based on the parameters that are listed in the population master table to define the uniqueness of a population member. An agent factory is built to define the population data and behavioural rules, and a synthetic population of the studied region is generated, chosen by the user to be large enough for a statistically representative sample of all variation in the population (e.g. several thousand to over ten thousand agents as proportional to the total population). The behaviours of each agent, as defined by their individual characteristics, lead to the final demand for resources, which can be tracked per agent or per district in which the agents live and work. A user interface is developed to simulate the selected region with flexibility to change agents and simulation settings, such as factors to fit consumption levels per person, tariffs of resource usage, and human faecal waste generated per toilet use.

The design concepts adopted by the platform are explained by the procedures of demand-side simulation first:

1. The synthetic population is generated from a pre-processed master table that represents the actual population with socio-economic variants.

2. The demands for water, electricity and other resources are estimated based on agents' activities in all zones defined in the context manager.

3. Output data is visualized and connected to optimization model.

The key outputs of the model as emerging from the individuals' traits are the aggregated demands in each region. The environment including natural (e.g., temperature, precipitation) and social perspectives (e.g., transportation status, income levels) can drive people or agents to change their behaviours with respect to resource consumption. Most importantly, the model is able to make predictions of societal changes under future scenarios when the economy evolves and therefore generate demand profiles in the target year for sustainable development goals to be met. The stochastic feature is also captured by inserting random variables into each agent's behaviour rules as compensation for neglecting interactions among agents.

All agents are initialized using the agent factory associated with the master tables and distributed by population density in each zone of the whole context. A simulation over one day starts from $0 \mathrm{am}$, from which on the behavioural rules are defined by input data based on temporal and spatial activities corresponding to their characteristics. A representative demonstration of input is listed in equation (4) where a whole set of activities $N$ is introduced to describe the activity patterns $A P_{a}$ of each agent $a$. Each specific activity $n\left(A C T_{n}\right)$ is conducted at the mean starting time $M T_{n}$ with a standard time 
deviation of $S D_{n}$ and a probability of starting $P S_{n}$. These probability-based models can fully describe all agents' activities and denote their locations at each time step.

$$
A P_{a} \square\left\{\left(A C T_{n}, M T_{n}, S D_{n}, P S_{n}\right)\right\}_{a}, \forall n \in N
$$

On top of the activities, the time-varying consumption of water, energy and other resources is analysed and described by regression functions from reported and survey data (Metcalf \& Eddy, Tchobanoglous, G., Stensel, D. H., Tsuchihashi, R., \& Burton, 2003). The time-dependent formulae are tested and validated by comparison with historical and current trends so they can describe the tendency and value range of demand data. According to the activity-based usage data patterns, regression functions, such as polynomial or sum of sine regression models are adopted to estimate diurnal patterns within the desired goodness-of-fit level. In this case, not only are residential water and energy demands obtained through agent-based simulation, but also the demands from industrial, commercial, and institutional operations are aggregated from the company master tables by their average usage. For the energy sectors in the following case study, the usage is converted into electric energy in units of MJ or $\mathrm{kWh}$ for direct supply-demand matching. The multi-agents simulation can provide information on water, energy and other resource consumption on a fine-grained spatial and temporal scale when used independently. On the other hand, it can also be combined with socio-demographic forecasts and the resourcetechnology network to fit the insufficient or unreliable data sources for the optimization model.

\subsection{Resource-technology network modelling for optimal supply}

The RTN component further uses the generated spatiotemporal demands to dispatch the supply side according to the current and future infrastructure and associated investment and operational costs as well as greenhouse gas (GHG) emissions. The optimization is based on a comprehensive technology datasets, part of which is outlined in Table 1 below.

Table 1. Key facts of technology datasets for source water treatment, wastewater treatment, and electricity generation (Wang et al., 2017).

\begin{tabular}{|c|c|c|c|c|}
\hline $\begin{array}{c}\text { Technology } \\
\text { Process Block }\end{array}$ & $\begin{array}{c}\text { Typical } \\
\text { Nameplate } \\
\text { Capacity }\end{array}$ & CAPEX/ USD & $\begin{array}{c}\text { O\&M } \\
\text { Costs/ } \\
\text { USD per } \mathbf{m}^{3} \\
\text { or kWh } \\
\end{array}$ & $\begin{array}{c}\mathrm{GHG} / \\
\mathrm{kg} \mathrm{CO} \text { eq } \\
\text { per } \mathrm{m}^{3} \text { or } \\
\mathrm{kWh}\end{array}$ \\
\hline $\begin{array}{l}\text { Central source water } \\
\text { treatment plant }\end{array}$ & $\begin{array}{c}10,950,000 \mathrm{~m}^{3} \text { per } \\
\text { year }\end{array}$ & $45,197,947$ & 0.230 & 0.017 \\
\hline $\begin{array}{c}\text { Borehole pumping } \\
\text { systems }\end{array}$ & $\begin{array}{c}150,000 \mathrm{~m}^{3} \\
\text { per year }\end{array}$ & $3,325,541$ & 0.337 & 0.0065 \\
\hline Bottled water packaging & $\begin{array}{l}14,400 \mathrm{~m}^{3} \\
\text { per year }\end{array}$ & $2,478,334$ & 302 & 2.10 \\
\hline Sachet water packaging & $1,100 \mathrm{~m}^{3}$ per year & 43,065 & 25.6 & 1.39 \\
\hline $\begin{array}{l}\text { Desalination treatment } \\
\text { plant }\end{array}$ & $\begin{array}{c}21,900,000 \mathrm{~m}^{3} \text { per } \\
\text { year }\end{array}$ & $130,000,000$ & 1.50 & 4.27 \\
\hline
\end{tabular}




\begin{tabular}{|c|c|c|c|c|}
\hline $\begin{array}{c}\text { Central wastewater } \\
\text { treatment plant }\end{array}$ & $\begin{array}{c}6,935,000 \mathrm{~m}^{3} \text { per } \\
\text { year }\end{array}$ & $53,398,778$ & 0.190 & 0.04 \\
\hline $\begin{array}{c}\text { Decentralized activated } \\
\text { sludge treatment }\end{array}$ & $\begin{array}{c}478,124 \mathrm{~m}^{3} \\
\text { per year }\end{array}$ & $1,516,850$ & 0.206 & 0.01 \\
\hline $\begin{array}{c}\text { Waste stabilization } \\
\text { ponds }\end{array}$ & $\begin{array}{c}2,748,450 \mathrm{~m}^{3} \text { per } \\
\text { year }\end{array}$ & $14,145,810$ & 0.255 & 0.38 \\
\hline $\begin{array}{l}\text { Active aerated closed } \\
\text { tank microbial treatment }\end{array}$ & $12,775 \mathrm{~m}^{3}$ per year & 244,500 & 1.21 & 0.01 \\
\hline \multirow{2}{*}{$\begin{array}{c}\text { Anaerobic } \\
\text { digestion/biogas }\end{array}$} & $\begin{array}{l}73 \mathrm{~m}^{3} \text { per year } \\
\text { (Farm) }\end{array}$ & 3,092 & 0.070 & 0 \\
\hline & $\begin{array}{c}850,122 \mathrm{~m}^{3} \text { per } \\
\text { year (Large) }\end{array}$ & $7,711,704$ & 0.0139 & 0.022 \\
\hline \multirow{2}{*}{$\begin{array}{c}\text { Fossil-fuel power } \\
\text { stations }\end{array}$} & $250 \mathrm{MW}$ (Coal) & $3,118,121,818$ & 0.0264 & 5.933 \\
\hline & $125 \mathrm{MW}$ (Gas) & $339,200,683$ & 0.0350 & 2.203 \\
\hline \multirow{2}{*}{ Hydroelectricity stations } & 1 MW (Small) & $7,287,273$ & 0.0130 & 0.0237 \\
\hline & 590 MW (Large) & $3,125,979,139$ & 0.00716 & 0.0243 \\
\hline \multirow{2}{*}{$\begin{array}{l}\text { Photovoltaic solar } \\
\text { power stations }\end{array}$} & $10 \mathrm{MW}(\mathrm{PV})$ & $72,081,785$ & 0.000304 & 0.121 \\
\hline & $\begin{array}{l}25 \text { MW (Solar } \\
\text { thermal) }\end{array}$ & $288,011,509$ & 0.0436 & 0.098 \\
\hline \multirow{2}{*}{ Wind power stations } & 1.5 MW (Onshore) & $6,526,731$ & 0.0178 & 0.035 \\
\hline & 1.8 MW (Offshore) & $18,449,956$ & 0.0504 & 0.0107 \\
\hline
\end{tabular}

257 These parameters for the "process blocks" built in the model are derived from reported or experimental 258 data, material flow analysis, and life cycle assessment. Each number used in the model is calibrated 259 across multiple sources and available in the platform as a technology database. The interrelationship 260 between the water and energy systems is addressed through material and energy balances at the whole 261 system, district and technology levels.

262 The main optimization problem is formulated as a mixed-integer linear programming (MILP) with an objective function described in equations (5) and (6) to minimize the multi-objectives of capital expenditures (CAPEX), operating expenditures (OPEX), and environmental impacts quantified by 265 GHG emissions.

$$
Z=\sum_{m} W T(m, t m) \times V M(m, t m)
$$

$W T(m, t m)$ represents weighting factors for all metrics $m$,

$$
\begin{aligned}
V M(t, t m) & =\sum_{j} \sum_{i} V I J(j, i, m) \times I N V(j, i, m)+\sum_{j} \sum_{i} \sum_{t} V P J(j, i, t, m) \times P(j, i, t, m) \\
& +\sum_{i, i^{\prime}} \sum_{r} \sum_{t} V Q(r, t, m) \times \operatorname{dist}\left(i, i^{\prime}\right) \times Q\left(r, i, i^{\prime}, t, t m\right) \\
& +\sum_{i, i^{\prime}} \sum_{r} V Y(r, m) \times \operatorname{dist}\left(i, i^{\prime}\right) \times Y\left(r, i, i^{\prime}, t m\right) \\
& +\sum_{i} \sum_{r} \sum_{t} V I(r, t, m) \times I M(r, i, t, t m)
\end{aligned}
$$

Where $j$ technologies include electricity generation plants, water and wastewater treatment facilities.

269 Spatial districts are indicated by $i$ (and $i$ ' as an alias denoting a distinct district fort flows and 
connectivity). $m$ represents each term in the objective function including metrics for CAPEX, OPEX, and environmental costs. $t$ and $t m$ are both time periods but different scales as minor (peak, normal, offpeak hours during a day) and major (each year, or multiple years in a row), respectively. Finally, $r$ stands for the resources evaluated in the model including raw water, process chemicals, electricity, wastewater, solid waste, labour and many other related resources. For all terms that make up the total value of metrics in the objective function, $\operatorname{VIJ}(j, i, m)$ is the CAPEX of a single technology $j$ in district $i$, and $\operatorname{INV}(j, i, \mathrm{tm})$ is additional investment of technology $j$ in district $i$ during time period $t m$. VPJ $(j, i$, $m$ ) is the metric of OPEX to operate technology $j$ in district $i$, and $P(j, i, t m)$ is the production rate of technology $j$ in district $i$ during time period $t m$. $V Q(r, m)$ is the unit cost associated with resource $r$ flowing, and $Q\left(r, i, i^{\prime}, t, t m\right)$ is the total flow rate of resource $r$ from district $i$ to $i$ ' during time period $t$ and $t m$. It is noted that the cost of flowing resources is also distance dependent so that the unit flow costs is multiplied by the distance between two ends $i$ and $i$ '. Similarly, the costs of building additional connections between two points for resource $r$ from district $i$ to $i$ ' equals the unit cost of pipeline/grid $V Y(r, m)$ multiplied by distance, while the binary variable $Y(r, i, i, t m)$ denotes the existence of a connection or expansion. Last, the $V I(r, m)$ is the unit cost of importing resource $r$ and $I M(r, i, t m)$ is the imported amount of resource $r$ into district $i$ during time period $t m$.

The optimization model has a set of constraints categorized to:

Technology and Investment balance/ limits,

$$
N(j, i, t m)=N(j, i, t m-1)+I N V(j, i, t m)
$$

Resource balance and capacity limits- mass and energy balance,

$$
D(r, i, t, t m)=M U \times P(j, i, t, t m)+Q\left(r, i^{\prime}, i, t, t m\right)-Q\left(r, i, i^{\prime}, t, t m\right)+I M(r, i, t, t m)
$$

Production limits based on capacities that account the total instalments $(N)$, individual capacity $(C A P)$, and capacity factor $(C F)$ :

$$
P(j, i, t, t m) \leq N(j, i, t m) \times C A P(j) \times C F(j)
$$

The flow limits based on pipe and grid connections and capacities are also posed, which are geometric distance related. Other realistic factors, including but not limited to pipe leakage and transmission loss, existing infrastructure set as a pre-allocation matrix, and ongoing construction projects are also incorporated in the model calculations.

\section{Case studies and results discussion}


To demonstrate its application, we use the platform to analyse energy-water nexus focusing on the provisioning of clean water-sanitation and electric power. The use cases are conducted for the city region of the Greater Accra Metropolitan Area (GAMA) in Ghana to enhance the local management of their urban environment and frame decision-making. The city is by functional definition divided into 15 districts and studied with respect to their demographics, resource requirement and development plans. The base year of 2010 has an actual description of the full state of the focused region, with accurate information of populations and existing infrastructure from census, reports, literature and local sources (Ghana Statistical Service, 2012; International Energy Agency (IEA), 2016).

The initial results show the population evolvement in GAMA from base year 2010 to 2030 with projected demographic developments. The incremental population growth every five years is indicated in Fig. 2 based on the social-demographic module prediction. The total population of the studied area is estimated to increase from 3.88 million in 2015 to 6.49 million in 2030, resulting a 67\% increase owing to the emerging urbanization trend. The age distribution, employment rate and social structure are also updated every year. The master table associated with the case study outlines characteristics such as gender (female or male), age categories (0-14/15+ years old), workforce status (employed, not active, or unemployed), and income levels (low, medium, and high), access to water pipelines and sanitation facilities. This is used as the basis for all scenarios of demand simulation and supply optimization in the energy-water nexus.

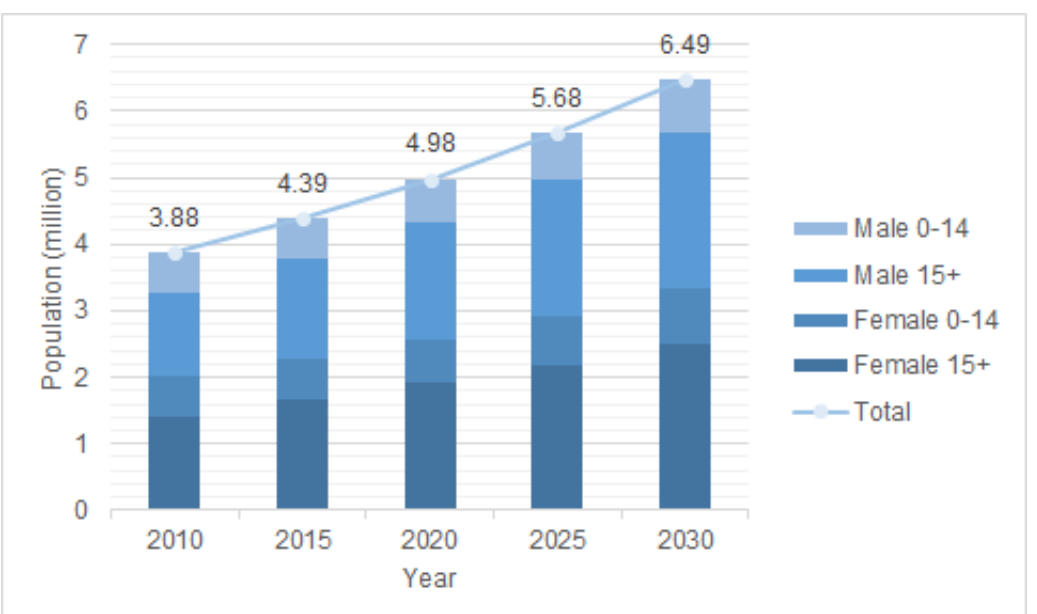

Fig. 2 Population and demographic forecast of the studied GAMA region as foundation for social-economic simulation.

\subsection{Energy-water Nexus in global practice}

318 Integrated resource management crossing multiple sectors such as water, energy, land use, food and waste from a nexus perspective can bring innovative insights and synergies in a whole system assessment (Foley et al., 2011; Liu et al., 2015). To show the economic and environmental benefits compared with an isolated plan, a study of the water, sanitation, and hygiene (WASH) sector is first 


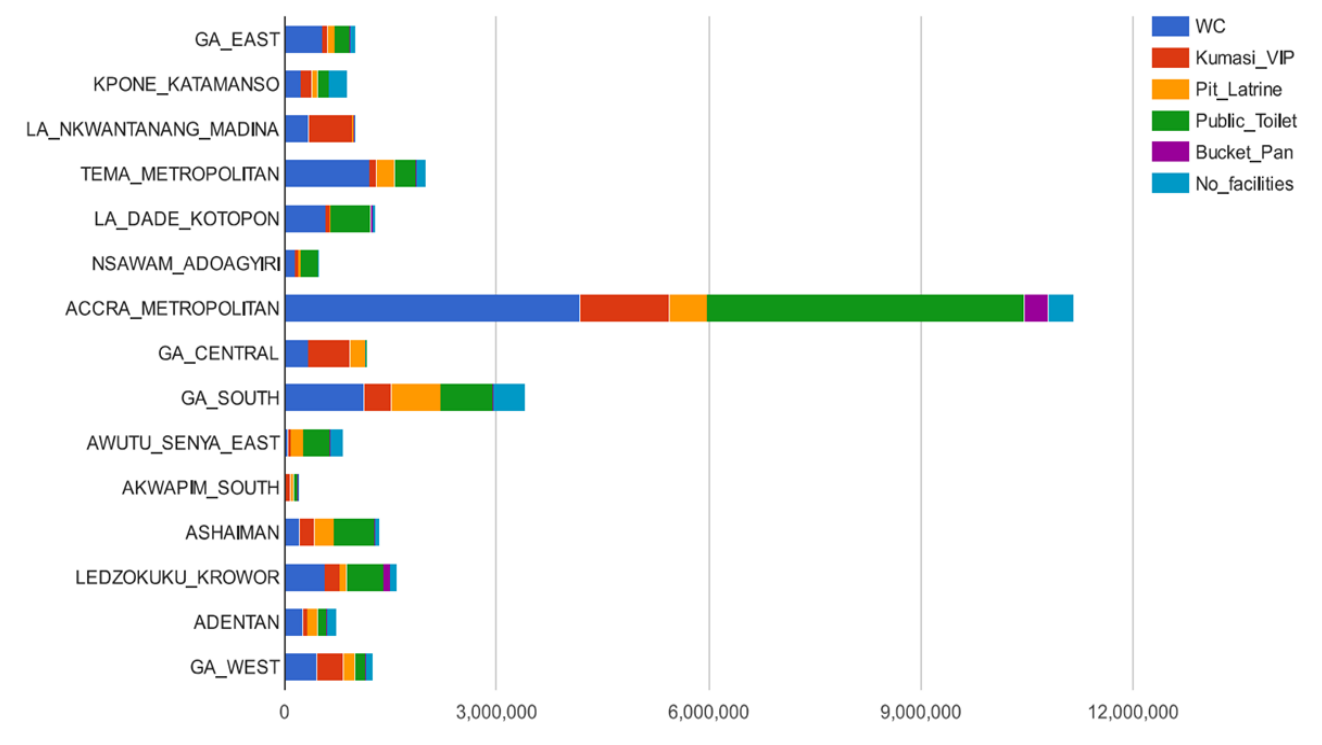

Total toilet use per district per day

(a)

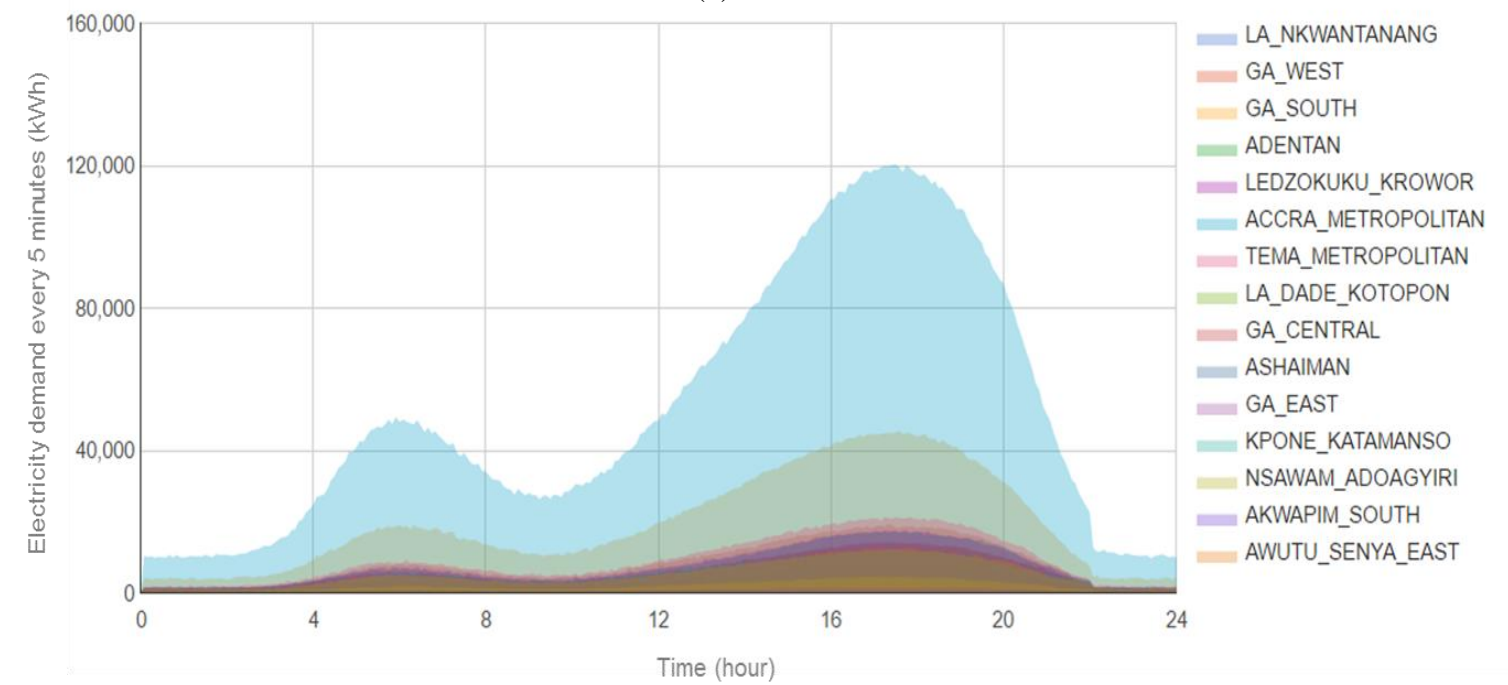

(b)

Fig. 3 Temporal and spatial resource demand profiles are generated from activity models and visualized: (a) Total toilet use per district per day. (b) Electricity demand as demonstrated per district over 24 hours daily in year 2030 .

carried out using the proposed methodology and platform. Profiles of water demand and wastewater production from daily activities in the studied regions are captured over a day for all citizens, while the aggregated yearly demand is obtained for future planning as the population and social-economic conditions develop with time. The total water demand increased from 126 million $\mathrm{m}^{3}$ per year for the studied region in 2010, to 215 million $\mathrm{m}^{3}$ in 2030, as projected by the simulation model. Similarly, metrics such as the wastewater to be treated for each year or more segmented indicators for genders, income levels and other categories are also calculated in the results dataset as a basis for the supply side optimization. As another key part of WASH in urban development, the sanitation problem is simultaneously analysed by considering people's behaviour of toilets use in daily activities. The 
required amount of facilities are accounted by summing up visiting times at each location, considering that the probability of satisfying rigid demand (e.g., excretion) increases with time as defined by individual agent's behaviour rules, the results of which are visualized in Fig. 3(a). The gap between current facilities and actual requirements for infrastructure indicate that an additional 234,000 private toilets and 2,500 public toilets are required on top of current conditions, and the total GAMA faecal sludge generated is to reach $8,700 \mathrm{~m}^{3}$ per day in 2030, when the Sustainable Development Goals aim to cover $100 \%$ toilets usage and waste treatment.

Based on the demand simulation results, the subsequent supply side optimization module selects optimal investment and operation strategies for water treatment and distribution facilities to meet the increasing demand and SDGs. The model is initialized with the currently existing treatment plants and network, such as the centralized source water treatment plants in Ga South Metropolitan Area (GSMA) and Volta River region that satisfy $34 \%$ of total potable water demand at present. In the business-asusual case, only $20 \%$ of the total demand in 2030 can be served by the current capacity. Therefore the scientific planning of a sustainable development of its regional WASH sector is highly necessary. As the results shown in Fig. 4(a) for example, the suggested annual production rate of source water treatment plants for each district is visualized automatically from the platform. The maximum capacity is installed in Accra Metropolitan Area (AMA) due to the large number of population and corresponding resource demand, with an 88.8 million $\mathrm{m}^{3}$ per year production rate of treated potable water from the expanded facilities. The optimization program also selects GSMA and several other regions as optimal locations for investing additional source water treatment plants due to their geographical and economic advantages. In addition, the flows of treated potable water among districts via existing or expanded pipe infrastructure are illustrated in Fig. 4(b) as part of the development plans. The leaks through pipelines is a serious issue for the local water sector, the impact of which is also accounted in the scenarios by simulating various leakage ratios and repairing strategies.

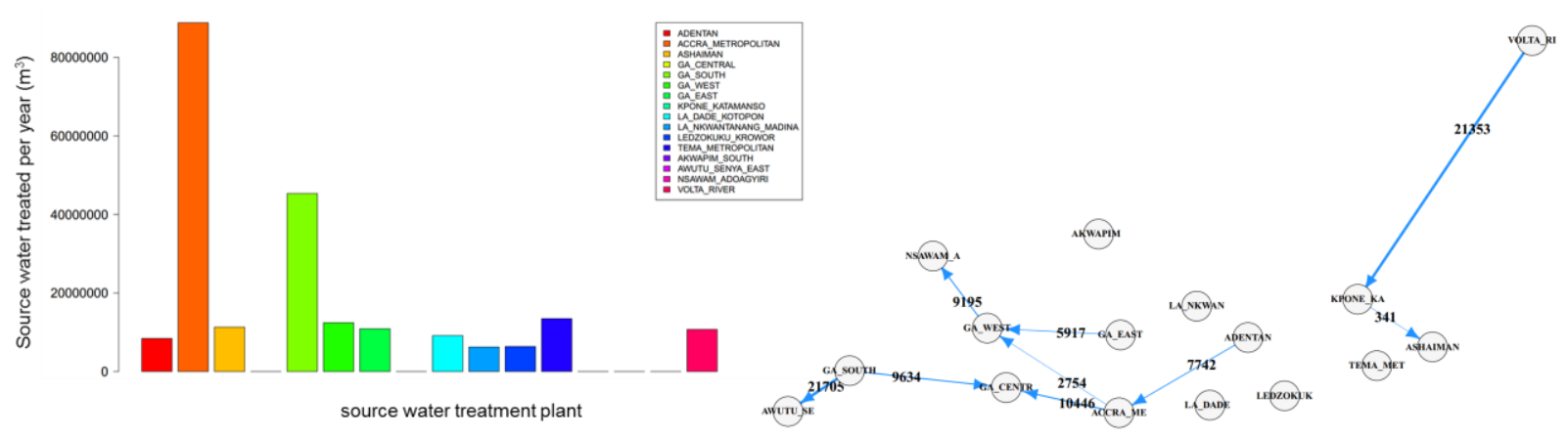

(a)

(b)

Fig. 4 Operational and investment strategies per district to meet $100 \%$ clean water supply targets by the year 2030 (directly generated from the platform): (a) Production rates of source water treatment plants per district. (b) Transportation and flows of potable water $\left(\mathrm{m}^{3}\right.$ per day). 
Moreover, for the wastewater treatment system that is to be constructed from a less developed state, decentralized treatment sites with appropriate technologies are suggested by the model to be more efficient especially with respect to operating costs and GHG emissions. By expanding conventional water treatment at existing sites with building more efficient pipe distribution, accompanied by decentralized capacity of smaller-scale wastewater treatment systems, this combined strategy is proved to be more cost-effective in terms of a $16.3 \%$ reduction (410 million USD that is equivalent to 63.2 USD per capita) in capital expenditure and 8.5\% (45 million USD, or 6.9 USD per capita) in operational costs per year on average, compared with the city-wide central supply or fully decentralized systems scenarios. More detailed operational and investment strategies to meet $100 \%$ clean water supply and wastewater treatment targets by the year 2030 are available in the result files returned from the platform use directly.

We can now demonstrate how the urban energy-water systems and their nexus are studied as a whole in the platform. The aim is to satisfy the rising energy demand associated with urban agglomerations including the requirement from the above studied WASH sector, but also to meet renewable energy targets that are set worldwide to provide sustainable energy supply and mitigate climate change risks. The electricity demand of the whole population is simultaneously estimated from agents' temporal and spatial activity simulation as presented in Fig. 3(b) earlier, as a normal demand scenario. The results of power mix design from co-optimizing water and energy sectors to obtain minimum economic and environmental costs are illustrated in Fig. 5 under the low-consumption scenario. From the base year of 2010 to future prediction into a 20-year development plan, a substantial increase in renewable generation capacity including photovoltaic (PV), wind and small hydro power stations is suggested. Demand increase, environmental adaptations, cost changes and potential policy intervention decide the future power mix all together. Besides the local generation plants, the required electricity can also be imported from other regions such as the West African Power Pool (WAPP) as an integrated regional electricity market. The balance between generation within the region and importing through transmission network is impacted by the real-time price to purchase electricity from the grid, which is

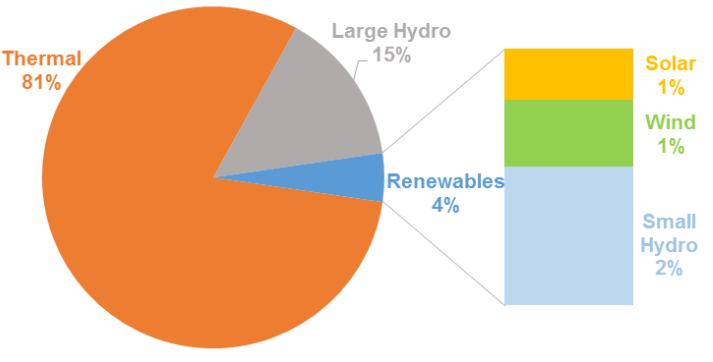

(a)

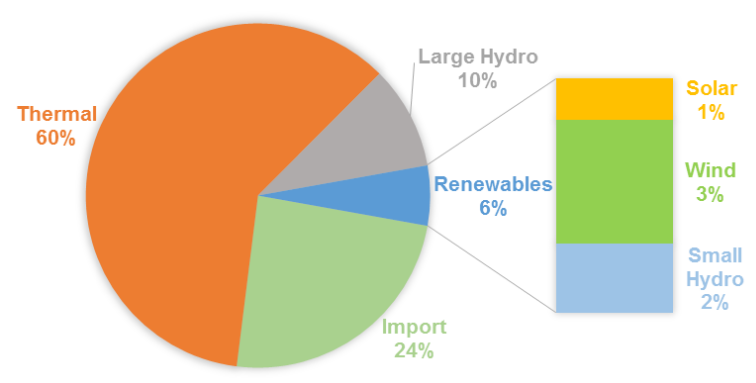

(b)

Fig. 5 Optimal local power mix in a scenario to adopt mediate level consumption with time evolvement: (a) Base year 2010, (b) Future scenario 2030. 
a user-defined input in the model. A sensitivity analysis over the costs of imported electricity suggests partially relying on power pool importing is advantageous when it costs less than 0.342 USD per kWh in 2030, as results shown in Fig. 5(b) with 24\% of total electricity imported from neighbourhood regions at a 0.187 USD per kWh import cost estimate. The electricity supply is also used to meet the water sector's extensive power requirement considering the local expansions in source water treatment plant capacity, besides providing electricity to residential and other users. Sensitivity analysis has been fully conducted in the supplementary information.

\subsection{Effectiveness in governmental cross-sectors co-operative decision-making}

The resilience.io serves as an open-access decision support platform for not only understanding the overall energy-water landscape of the studied urban area, but also providing an environment for multiple sectors to collaboratively propose sustainable development strategies. This systematic approach leads to an affordable low-carbon development road map in the long term globally, with socio-economic scenarios addressed through continuous updates, forecasting and feedback over the whole system.

The detailed costs breakdown based on the modelled investment and operation strategies from cooptimizing the WASH and energy sectors in different scenarios are listed in Table 2.We highlight that the quantified environmental impacts along with economic costs of water and power systems as well as their nexus are obtained and compared. The conserved low-consumption scenarios are associated with lower demands of electricity to be satisfied, compared with the normal consumption scenarios that aim to satisfy individuals' unmitigated demand with a trade-off in higher costs. The results prove that an aggressive investment plan to satisfy demand during 2010 to 2020 can compensate a major part of capital expenditures since then. Therefore, with scientific long-term planning, the infrastructure construction will not cause incremental investment although the population and corresponding demand are significantly increasing. A flexible financial model combined with this decision-support evidence is promising to attract funding from global investments or urban development funds, while the operational costs are reasonably affordable on a per capita basis from either utility bills or tax income.

Table 2. Economic and environmental results in different consumption scenarios for 2010-2030.

\begin{tabular}{|c|c|c|c|c|c|}
\hline \multirow{2}{*}{ Scenarios } & \multicolumn{2}{|c|}{ Overall for water and energy sectors } & \multicolumn{2}{c|}{ Per capita } \\
\cline { 2 - 6 } & $\begin{array}{c}\text { CAPEX/ } \\
\text { USD }\end{array}$ & $\begin{array}{c}\text { OPEX/ } \\
\text { USD per } \\
\text { year }\end{array}$ & $\begin{array}{c}\text { GHG/ tonnes } \\
\mathrm{CO}_{2} \text { eq }\end{array}$ & $\begin{array}{c}\text { OPEX/ } \\
\text { USD per } \\
\text { year }\end{array}$ & $\begin{array}{c}\text { GHG/ tonnes } \\
\mathrm{CO}_{2} \text { eq }\end{array}$ \\
\hline $\begin{array}{c}\text { Conserved low- } \\
\text { consumption in 2010- } \\
\text { 2020 }\end{array}$ & $\begin{array}{c}86.7 \\
\text { billion }\end{array}$ & 199 million & 6.36 million & 51.3 & 1.64 \\
\hline $\begin{array}{c}\text { Conserved low- } \\
\text { consumption in 2020- } \\
\text { 2030 }\end{array}$ & $\begin{array}{c}0.312 \\
\text { billion }\end{array}$ & 489 million & 7.19 million & 75.3 & 1.11 \\
\hline
\end{tabular}




\begin{tabular}{|c|c|c|c|c|c|}
\hline $\begin{array}{c}\text { Normal consumption in } \\
2020-2030\end{array}$ & $\begin{array}{c}14.5 \\
\text { billion }\end{array}$ & 928 million & 22.2 million & 142.9 & 3.43 \\
\hline $\begin{array}{c}\text { Low-carbon development } \\
\text { in 2020-2030 }\end{array}$ & $\begin{array}{c}0.361 \\
\text { billion }\end{array}$ & 727 million & 3.48 million & 112.0 & 0.54 \\
\hline
\end{tabular}

407

408 Moreover, although climate change mitigation has not been widely addressed in African countries, the 409 continuous increase of international carbon trading prices should start to drive the whole urban energy 410 system strictly towards clean energy technologies. Besides increasing renewable power generation, 411 carbon capture and storage technology is gradually integrated into the system to test the technologies' 412 potential at an early stage. Therefore, we consider a low-carbon development scenario to return a set of 413 planning decisions from the platform use. The total GHG emissions associated with the water, sanitation 414 and electricity supply are minimized to 3.48 million tonnes which correspond to 0.56 tonnes $\mathrm{CO}_{2}$ 415 equivalent per capita per year in 2030, resulting a $51.4 \%$ reduction compared with the conserved low416 consumption scenario meeting the same demand but using more carbon-intensive technologies. The 417 case studies in Africa can be extended to other regions to set up global practices. When the government 418 is designing long-term development plan, it is essential to shape a consistent path regardless of regime 419 changes.

The platform is not only used to test and plan conventional infrastructures, it is also capable of incorporating innovative technologies or strategies to provide preliminary feasibility test and market investment assessment. For example, in this case an innovative decentralized water treatment technology using solar heating to purify water from any source is integrated into the water supply system for a comparative analysis. The results suggest that if this technology is compared with general potable water supply facilities, it has no advantage due to its small capacity. However, this treatment produces clean potable water that can meet the drinking quality standards, so that it could substitute sachet water or bottled water, which are two major supply sources for drinking water if there is no pipeline connection. When specifically focusing on the drinking water supply for human intake, the new technology shows economic viability and positive environmental contributions. The demand of drinking water is estimated from the agent activity based simulation to be around 3.47 million $\mathrm{m}^{3}$ per year for the whole region as predicted in year 2020. While this innovative facility as a standalone device, currently has a capacity of $4.2 \mathrm{~m}^{3}$ per year, with CAPEX of 500 USD for each equipment, and OPEX around 50 USD each year. It has potential to be more cost-effective and selected as a promising alternative for drinking water supply with lower costs than bottle water supply. Moreover, either central desalination plants or decentralized seawater treatment devices can serve as a viable option to produce 
potable water. When the prices of new technologies are lowered, this distributed technology has the potential to beat traditional desalination as a sustainable and affordable clean water source.

\section{Conclusions and future work}

This paper has introduced a decision support system including methodology and case studies to design and operate urban systems, especially the water and energy sectors addressing their nexus. This platform also allows a flexible integration of new technologies to test their feasibility of application in the studied regions, with a set of technologies built with respect to their technical, economic, environmental specifications. Therefore, a main contribution of this paper is the combination of simulation and optimization using widely available data to provide decision support for policy makers in urban systems planning. In the meanwhile, more technology vendors and stakeholders can also benefit from the platform by understanding and exhibiting the costs and benefits of their technologies for energy production or water treatment when integrated into the whole urban system. Moreover, long-term socioeconomic scenarios are addressed in the urban system development through the continuous wholesystem update, forecast and feedback. It leads to an affordable low-carbon development road map in the long term globally. In addition to the simulation and optimization modules, the platform also provides an automatic visualization of results with interactive figures to present the full set of information. The continuous development of the collaborative platform in future work will incorporate more details such as the availability of renewable energy generation on a more frequent time series and associated costs of intermittency. Also, water and energy storage technologies especially those combining both systems such as pumped hydroelectric storage are promising to be incorporated and addressed in the next phase of the model. More case studies to apply this universal methodology and platform to other regions worldwide are also in development.

\section{Nomenclature}

\section{Acronyms}

$\begin{array}{ll}\text { ABM } & \text { Agent-Based Modelling } \\ \text { AMA } & \text { Accra Metropolitan Area (AMA) } \\ \text { CAPEX } & \text { Capital expenditures }\end{array}$


$\mathrm{CO}_{2}$ eq Equivalent carbon dioxide emissions

GAMA Greater Accra Metropolitan Area

GHG Greenhouse Gas

GIS Geographic Information Systems

GSMA Ga South Metropolitan Area (GSMA)

GWC Ghana Water Company

IEA International Energy Agency (IEA)

MILP Mixed-integer linear programming,

ODD Overview, Design concepts, and Details

OPEX Operating expenditures

PV Photovoltaic

RTN Resource-Technology Network

SDG Sustainable Development Goals

WAPP West African Power Pool

WASH Water, sanitation, and hygiene

466 Symbols

$A C T_{n}$

$A P_{a}$

CAP

$C F$

$E_{\max }$

$E C R$

$\operatorname{IM}(r, i, t m)$

$\operatorname{INV}(j, i, t m)$

$M T_{n}$

$N_{\text {company }}$

$N(j, i, t m)$

$D(r, i, t, t m)$
Agent specific activity $n$

Agent probability-based description of each agent $a$

Capacity limit of technology $j$

Capacity factor (efficiency) of technology $j$

Employment maximum level

Employment change rate

Imported amount of resource $r$ into district $i$ during time period $t m$

Additional investment of technology $j$ in $i$ during time period $t m$

Mean starting time of an agent activity $n$

Numbers of companies and institutes

Total amount of technology $j$ in district $i$ during time period $t m$

Resource demand of $r$ in district $i$ during time period $t$ and $t m$ 


$\begin{array}{ll}P(j, i, t m) & \text { Production rate of technology } j \text { in district } i \text { during time period } t m \\ P S_{n} & \text { Probability of starting of an agent activity } n \\ Q(r, i, i, t, t m) & \text { Total flow rate of resource } r \text { from district } i \text { to } i \text { ' during time period } t \text { and } t m \\ S D_{n} & \text { Standard time deviation of an agent activity } n \\ r_{e m p} & \text { Employment ratio } \\ V I(r, m) & \text { Unit cost of importing resource } r \\ V I J(j, i, m) & \text { Metric of CAPEX of a single technology } j \text { in district } i \\ V P J(j, i, m) & \text { Metric of OPEX to operate technology } j \text { in district } i, \\ V Q(r, m) & \text { Unit cost associated with resource } r \text { flowing } \\ V Y(r, m) & \text { Unit cost of connection (e.g., pipeline/grid) for resource } r \text { flowing } \\ Y(r, i, i, t m) & \text { Existence of a connection or expansion (binary variable) between } i \text { and } i \text { ' for } \\ Z & \text { resource } r \text { during time period tm }\end{array}$

\section{Subscripts}

$\begin{array}{ll}a & \text { Set of agent } \\ n & \text { Set of agent specific activity } \\ i & \begin{array}{l}\text { Set of spatial districts ( } i \text {, as an alias denoting a distinct district fort flows and } \\ \text { connectivity) }\end{array} \\ j & \begin{array}{l}\text { Set of technology (e.g., electricity generation plants, water and wastewater } \\ \text { treatment facilities) }\end{array} \\ m & \begin{array}{l}\text { Set of terms in the objective function including metrics for CAPEX, OPEX, and } \\ \text { environmental costs }\end{array} \\ r & \text { Set of resource (e.g., water, energy, and waste) } \\ t & \text { Set of minor time intervals (e.g., peak, normal, off-peak hours during a day) } \\ t m & \text { Set of major time intervals (i.e., years) }\end{array}$

\section{Acknowledgements}

471 The authors are grateful to the Department for International Development (UK) for financial support to 472 the Future Proofing African Cities for Sustainable Growth project (grant number 203830). X. Wang 473 thanks the MOE AcRF Grant in Singapore for financial support to the project "Pathways to resilient 474 Food-Energy-Water-Waste Nexus" (R-279-000-537-114). The Ghana Technical Group is gratefully 475 acknowledged for the useful discussions on data and case studies. We also deeply thank the Ecological 
Sequestration Trust for the platform delivery at http://resilience.io to disseminate results and case study results.

\section{References}

Anadon, L.D., Chan, G., Harley, A., Matus, K., Clark, W.C., 2015. Making Technological Innovation Work for Sustainable Development Faculty Research Working Paper Series.

Bai, X., Chen, J., Shi, P., 2011. Landscape urbanization and economic growth in China: positive feedbacks and sustainability dilemmas. Environ. Sci. Technol. 46, 132-139.

Brandoni, C., Bošnjaković, B., 2017. HOMER analysis of the water and renewable energy nexus for water-stressed urban areas in Sub-Saharan Africa. J. Clean. Prod. 155, 105-118. https://doi.org/10.1016/j.jclepro.2016.07.114

Case Studies - resilience.io, 2017.

Chen, S., Chen, B., 2016. Urban energy-water nexus: A network perspective. Appl. Energy 184, 905914. https://doi.org/10.1016/j.apenergy.2016.03.042

Clark, D., 2003. Urban world/global city. Psychology Press, Hove.

Coutinho-Rodrigues, J., Simão, A., Antunes, C.H., 2011. A GIS-based multicriteria spatial decision support system for planning urban infrastructures. Decis. Support Syst. 51, 720-726. https://doi.org/10.1016/j.dss.2011.02.010

Daly, H.E., Fais, B., 2014. UK Times Model Overview. UCL Energy Inst.

Dimitriadis, A., Shah, N., Pantelides, C.C., 1997. RTN-based rolling horizon algorithms for medium term scheduling of multipurpose plants. Comput. Chem. Eng. 21, S1061-S1066. https://doi.org/10.1016/S0098-1354(97)87643-0

Fiksel, J., 2003. Designing Resilient, Sustainable Systems. Environ. Sci. Technol. 37, 5330-5339. https://doi.org/10.1021/es0344819

Foley, J.A., Ramankutty, N., Brauman, K.A., Cassidy, E.S., Gerber, J.S., Johnston, M., Mueller, N.D., O’Connell, C., Ray, D.K., West, P.C., Balzer, C., Bennett, E.M., Carpenter, S.R., Hill, J., Monfreda, C., Polasky, S., Rockström, J., Sheehan, J., Siebert, S., Tilman, D., Zaks, D.P.M., O’Connell, C., 2011. Solutions for a cultivated planet. Nature 478, 337-342. https://doi.org/10.1038/nature10452

Gao, L., Bryan, B.A., 2017. Finding pathways to national-scale land-sector sustainability. Nature 544, 217-222. https://doi.org/10.1038/nature21694

Ghana Statistical Service, 2012. Population and housing census summary report.

Gleick, P., Ajami, N., 2014. The world's water volume 8: The biennial report on freshwater resources. Griggs, D., Stafford-Smith, M., Gaffney, O., Rockström, J., Öhman, M.C., Shyamsundar, P., Steffen, W., Glaser, G., Kanie, N., Noble, I., 2013. Policy: Sustainable development goals for people and planet. Nature 495, 305-307. https://doi.org/10.1038/495305a 
Grimm, V., Berger, U., Bastiansen, F., Eliassen, S., Ginot, V., Giske, J., Goss-Custard, J., Grand, T., Heinz, S.K., Huse, G., Huth, A., Jepsen, J.U., Jørgensen, C., Mooij, W.M., Müller, B., Pe’er, G., Piou, C., Railsback, S.F., Robbins, A.M., Robbins, M.M., Rossmanith, E., Rüger, N., Strand, E., Souissi, S., Stillman, R.A., Vabø, R., Visser, U., DeAngelis, D.L., 2006. A standard protocol for describing individual-based and agent-based models. Ecol. Modell. 198, 115-126. https://doi.org/10.1016/j.ecolmodel.2006.04.023

Grimm, V., Berger, U., DeAngelis, D.L., Polhill, J.G., Giske, J., Railsback, S.F., 2010. The ODD protocol: A review and first update. Ecol. Modell. 221, 2760-2768. https://doi.org/10.1016/j.ecolmodel.2010.08.019

Hastings, A., 2013. Population biology: concepts and models. Springer.

Hering, J.G., Waite, T.D., Luthy, R.G., Drewes, J.E., Sedlak, D.L., 2013. A Changing Framework for Urban Water Systems. Environ. Sci. Technol. 47, 10721-10726. https://doi.org/10.1021/es4007096

Hussey, K., Pittock, J., 2012. The energy-water nexus: Managing the links between energy and water for a sustainable future. Ecol. Soc. 17, 31. https://doi.org/10.5751/ES-04641-170131

International Energy Agency (IEA), 2016. World Energy Outlook 2016. Paris.

Jackson, J., 2010. Improving energy efficiency and smart grid program analysis with agent-based enduse forecasting models. Energy Policy 38, 3771-3780. https://doi.org/10.1016/j.enpol.2010.02.055

Kemausuor, F., Obeng, G.Y., Brew-Hammond, A., Duker, A., 2011. A review of trends, policies and plans for increasing energy access in Ghana. Renew. Sustain. Energy Rev. https://doi.org/10.1016/j.rser.2011.07.041

Kilkiş, Ş., 2016. Sustainable development of energy, water and environment systems index for Southeast European cities. J. Clean. Prod. 130, 222-234. https://doi.org/10.1016/j.jclepro.2015.07.121

Koppelaar, R.H.E.M., Sule, M.N., Kis, Z., Mensah, F.K., Wang, X., Triantafyllidis, C., Wang, X., Shah, N., 2018. Framework for WASH Sector Data Improvements in Data-Poor Environments, Applied to Accra, Ghana. Water 1-24. https://doi.org/10.3390/w10091278

Lam, K.L., Kenway, S.J., Lant, P.A., 2017. Energy use for water provision in cities. J. Clean. Prod. 143, 699-709. https://doi.org/10.1016/j.jclepro.2016.12.056

Lambert, T., Gilman, P., Lilienthal, P., 2006. Micropower System Modeling with Homer, in: Integration of Alternative Sources of Energy. John Wiley \& Sons, Inc., Hoboken, NJ, USA, pp. 379-418. https://doi.org/10.1002/0471755621.ch15

Liu, J., Mooney, H., Hull, V., Davis, S.J., Gaskell, J., Hertel, T., Lubchenco, J., Seto, K.C., Gleick, P., Kremen, C., Li, S., 2015. Systems integration for global sustainability. Science (80-. ). 347, 1258832. https://doi.org/10.1126/science. 1258832 
Lorek, S., Spangenberg, J., 2014. Sustainable consumption within a sustainable economy-beyond green growth and green economies. J. Clean. Prod. 63, 33-44.

Lu, Y., Nakicenovic, N., Visbeck, M., Stevance, A.-S., 2015. Five priorities for the UN Sustainable Development Goals. Nature 520, 432-433. https://doi.org/10.1038/520432a

Mandelli, S., Barbieri, J., Mattarolo, L., Colombo, E., 2014. Sustainable energy in Africa: A comprehensive data and policies review. Renew. Sustain. Energy Rev. 37, 656-686. https://doi.org/10.1016/j.rser.2014.05.069

Menger-Krug, E., Niederste-Hollenberg, J., Hillenbrand, T., 2013. Overview of material and energy flows in water infrastructures in context of urban metabolism, Urban Environment. Springer Netherlands, Dordrecht. https://doi.org/10.1007/978-94-007-7756-9_1

Metcalf \& Eddy, Tchobanoglous, G., Stensel, D. H., Tsuchihashi, R., \& Burton, F., 2003. Wastewater engineering: Treatment, disposal and reuse. McGraw Hill, New York. https://doi.org/10.1016/0309-1708(80)90067-6

Nilsson, M., Griggs, D., Visback, M., 2016. Map the interactions between Sustainable Development Goals. Nature 534, 320-322. https://doi.org/10.1038/534320a

Ramaswami, A., Russell, A.G., Culligan, P.J., Sharma, K.R., Kumar, E., 2016. Meta-principles for developing smart, sustainable, and healthy cities. Science (80-. ). 352, 940-943.

Samsatli, S., Samsatli, N.J., Shah, N., 2015. BVCM: A comprehensive and flexible toolkit for whole system biomass value chain analysis and optimisation - Mathematical formulation. Appl. Energy 147, 131-160. https://doi.org/10.1016/j.apenergy.2015.01.078

United Nations General Assembly, 2015. Transforming our world: The 2030 agenda for sustainable development, https://sustainabledevelopment.un.org/content/documents/7891Transforming\%20Our\%20World . pdf. https://doi.org/10.1007/s13398-014-0173-7.2

Urbaniec, K., Mikulčić, H., Duić, N., Lozano, R., 2016. SDEWES 2014 - Sustainable Development of Energy, Water and Environment Systems. J. Clean. Prod. 130, 1-11. https://doi.org/10.1016/j.jclepro.2016.04.062

Villarroel Walker, R., Beck, M.B., Hall, J.W., Dawson, R.J., Heidrich, O., 2014. The energy-waterfood nexus: Strategic analysis of technologies for transforming the urban metabolism. J. Environ. Manage. 141, 104-115. https://doi.org/10.1016/j.jenvman.2014.01.054 Wang, X., Guo, M., Koppelaar, R.H.E.M., van Dam, K.H., Triantafyllidis, C.P., Shah, N., 2018. A Nexus Approach for Sustainable Urban Energy-Water-Waste Systems Planning and Operation. Environ. Sci. Technol. acs.est.7b04659. https://doi.org/10.1021/acs.est.7b04659

Wang, X., van Dam, K.H., Triantafyllidis, C., Koppelaar, R.H.E.M., Shah, N., 2017. Water and Energy Systems in Sustainable City Development: A Case of Sub-saharan Africa. Procedia Eng. 198, 948-957. https://doi.org/10.1016/J.PROENG.2017.07.140 
583 Weitz, N., Persson, Å., Nilsson, M., Tenggren, S., 2015. Sustainable Development Goals for Sweden : $584 \quad$ Insights on Setting a National Agenda.

585 Zhang, C., Anadon, L.D., 2013. Life cycle water use of energy production and its environmental 586 impacts in china. Environ. Sci. Technol. 47, 14459-14467. https://doi.org/10.1021/es402556x 